\title{
Case Report \\ Rare Cause of Seizures, Renal Failure, and Gangrene in an 83-Year-Old Diabetic Male
}

\author{
Stalin Viswanathan and Kandan Balamurugesan \\ Indira Gandhi Medical College, Kadhiramam, Pondicherry 605009, India \\ Correspondence should be addressed to Stalin Viswanathan; stalinviswanathan@ymail.com
}

Received 12 May 2013; Accepted 11 June 2013

Academic Editors: A. M. Mansour and H. Narimatsu

Copyright ( $) 2013$ S. Viswanathan and K. Balamurugesan. This is an open access article distributed under the Creative Commons Attribution License, which permits unrestricted use, distribution, and reproduction in any medium, provided the original work is properly cited.

\begin{abstract}
We report an 83-year-old diabetic male who presented with acute-onset renal failure, seizures, psychosis, pneumonia, and right foot gangrene. Investigations revealed thrombocytopenia, CSF lymphocytosis, ANA and dsDNA positivity, hypocomplementemia, and pneumonitis following which he was treated with pulse methylprednisolone. He was treated for Pseudomonas-related ventilatorassociated pneumonia, candiduria, and E. coli-related bedsore infection prior to discharge. He was discharged at request and died 17 days later due to a respiratory infection.
\end{abstract}

\section{Introduction}

Onset of systemic lupus erythematosus (SLE) after the age of 50 (late-onset SLE) constitutes 6-18\% of the lupus population [1]. Most cases of lupus over 65 years have been described as case reports. Renal failure is the initial presentation only in $25 \%$ patients of SLE [2]. Neuropsychiatric SLE (NSLE) in the elderly is very rare. Infections, malignancies, and atherosclerotic disease account for most deaths in SLE patients [3]. Here we describe an 83-year-old diabetic who presented with acute-onset seizures, psychosis, pneumonitis, foot gangrene, and renal failure and improved with immunosuppressive therapy for SLE but succumbed to another respiratory infection 17 days after discharge from hospital.

\section{Case}

This 83-year-old diabetic of 10 years' duration (on metformin $750 \mathrm{mg}$ OD) was brought from another hospital by his relatives for mechanical ventilation. Fifteen days prior, he had complained of fatigue and anorexia and was admitted in a local nursing home where he was told to have early renal failure (creatinine $202 \mu \mathrm{mol} / \mathrm{L}$ ). Four days later he had had a generalized tonic-clonic seizure for which he was taken to the referring hospital for management. Computed tomography
(CT) of brain was normal and the patient was commenced on phenytoin; he was uncooperative for magnetic resonance imaging (MRI). He had developed acute psychosis and delirium in hospital and was managed with risperidone. Three days later he was intubated for altered sensorium and respiratory distress following acute cough, breathlessness, and fever. He was mechanically ventilated and administered ceftriaxone and metronidazole; his seizures remained under control but altered sensorium persisted. During his stay in intensive care, he developed discoloration of his right foot and warfarin had been initiated. His renal parameters had continued to worsen (creatinine $350 \mu \mathrm{mol} / \mathrm{L}$ ) and his relatives requested discharge and brought him to our hospital.

He was a cigar smoker ( $>40$ years) and drank occasionally. He had had a left hip fracture six years ago which had been treated conservatively. On admission, his pulse was $104 \mathrm{bpm}, \mathrm{BP} 92 / 60 \mathrm{~mm} \mathrm{Hg}$, respiratory rate 42 breaths/min with $\mathrm{SpO}_{2} 92 \%$ on $\mathrm{FiO} 2$ of 100 , temperature $99^{\circ} \mathrm{F}$, and central venous pressure (CVP) was $6 \mathrm{~cm}$. Chest examination revealed left-sided coarse crackles. The Glasgow Coma Scale (GCS) of $2 \mathrm{~T} / 15$, bilaterally $3 \mathrm{~mm}$ sluggishly reacting pupils, generalized hypotonia, and areflexia were observed on neurological examination. There was no papilledema. He had dry gangrene of right foot (Figure 1) with weak right popliteal pulse. Investigations are listed in Table 1. Doppler of right lower limb 


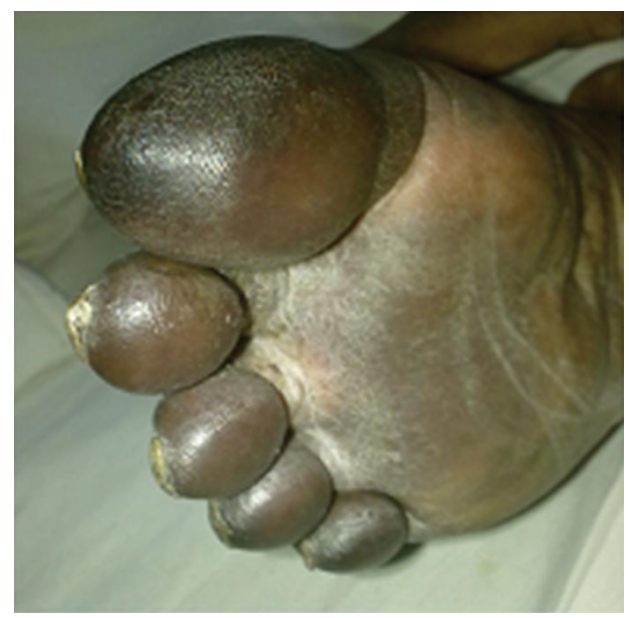

(a)

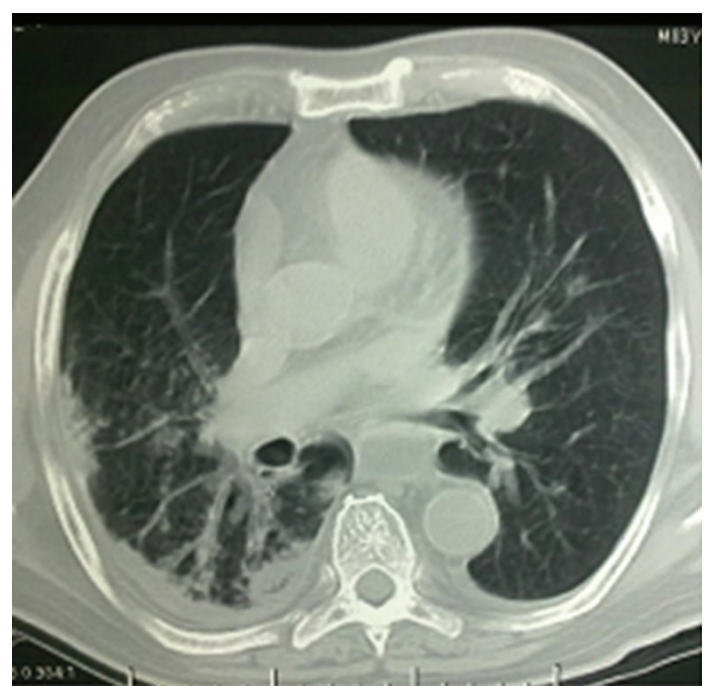

(c)

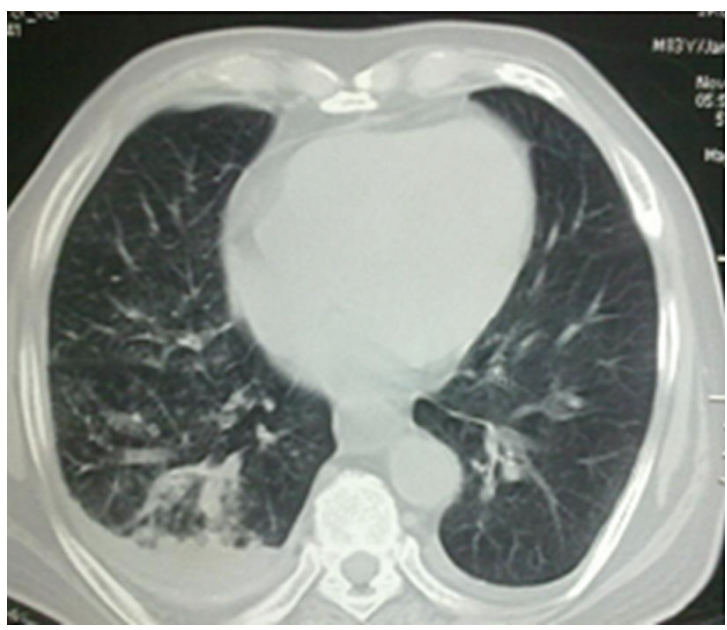

(e)

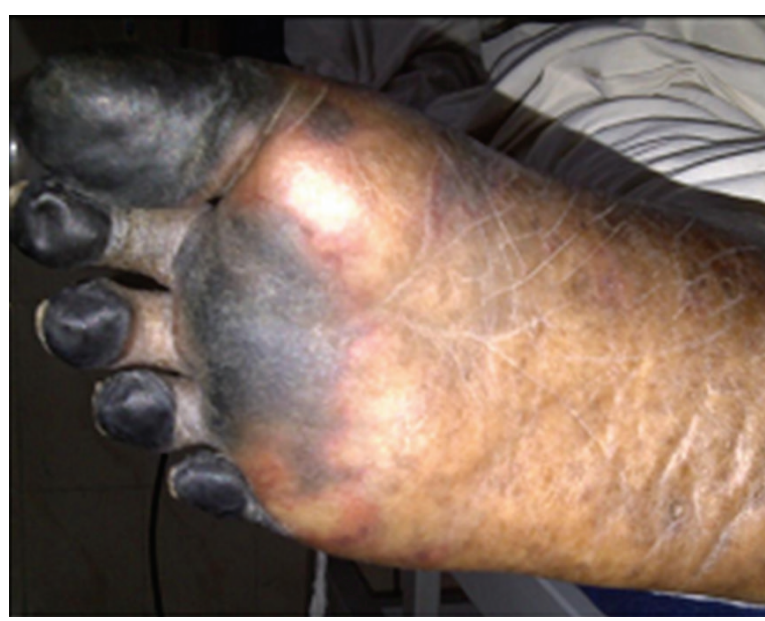

(b)

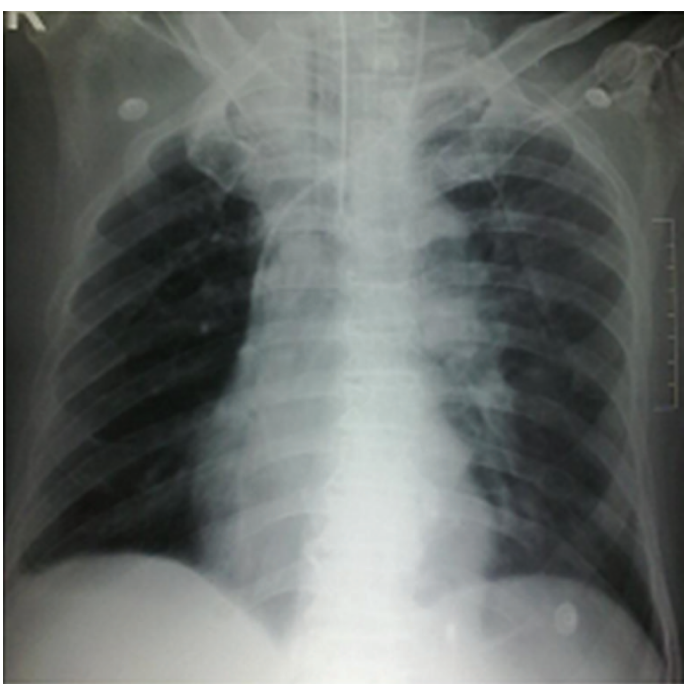

(d)

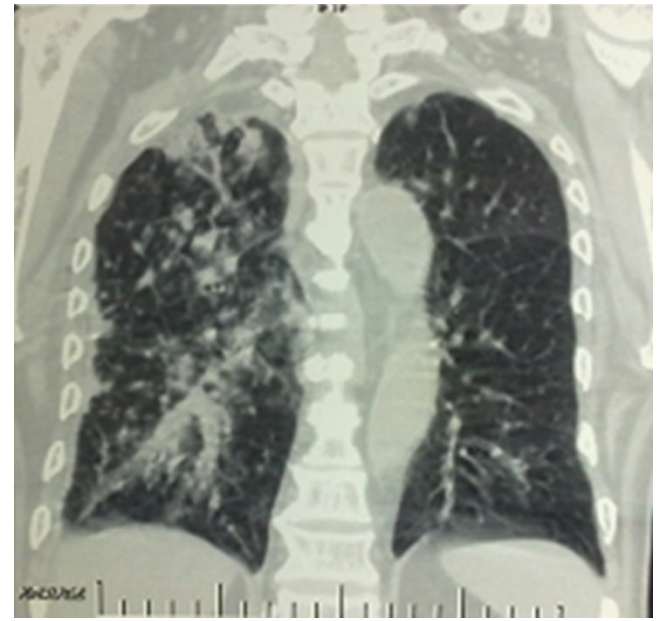

(f)

Figure 1: (a) Right foot discoloration at admission. (b) Right forefoot dry gangrene on day 4. (c) CT chest on day 2 showing airway dilatation (right predominant), patchy infiltrates, and ground glassing. (d) Chest radiograph on day 4 of admission shows clearing of infiltrates in the right side. (e) CT chest revealing right-sided pleural effusion, reticular infiltrates, bilateral ground glassing, and tree-in-bud appearance. (f) CT chest shows reticulonodular infiltrates in the entire right lung and ground glassing in left lung. 
TABLE 1: Lab investigations of patient.

\begin{tabular}{|c|c|c|c|c|c|c|c|}
\hline Day of admission & 1 & 4 & 5 & 7 & 10 & 16 & 18 \\
\hline Urea $(2.5-7.1 \mathrm{mmol} / \mathrm{L})$ & 67.8 & 61.7 & 47.1 & 38.7 & 33.2 & 26.4 & 21.1 \\
\hline $\begin{array}{l}\text { Creatinine } \\
(44-80 \mu \mathrm{mol} / \mathrm{L})\end{array}$ & 616 & 422 & 360 & 281 & 290 & 202 & 167 \\
\hline HbAlc (5.7-6.5\%) & 7.9 & & & & & & \\
\hline $\begin{array}{l}\text { Bil total } \\
(1.7-6.8 \mu \mathrm{mol} / \mathrm{L})\end{array}$ & 1.53 & & & & & & \\
\hline $\begin{array}{l}\text { Bil dir } \\
(3.4-15.2 \mu \mathrm{mol} / \mathrm{L})\end{array}$ & 8.5 & & & & & & \\
\hline $\begin{array}{l}\text { SGOT } \\
(0.20-0.65 \mu \mathrm{kat} / \mathrm{L})\end{array}$ & 1.5 & & & & 1.4 & & \\
\hline $\begin{array}{l}\text { SGPT } \\
(0.12-0.70 \mu \mathrm{kat} / \mathrm{L})\end{array}$ & 0.87 & & & & 0.92 & & \\
\hline $\begin{array}{l}\text { ALP } \\
(0.56-1.63 \mu \mathrm{kat} / \mathrm{L})\end{array}$ & 3.88 & & & & 9.02 & & \\
\hline Protein $(67-86 \mathrm{~g} / \mathrm{L})$ & 63 & & & & & & \\
\hline Albumin $(40-50 \mathrm{~g} / \mathrm{L})$ & 18 & 21 & 22 & 22 & & & \\
\hline $\begin{array}{l}\text { GGT } \\
(0.15-0.99 \mu \mathrm{kat} / \mathrm{L})\end{array}$ & 4.48 & & & & & & \\
\hline $\mathrm{K}^{+}(3.5-5.0 \mathrm{mmol} / \mathrm{L})$ & 5.6 & 3.3 & 3.9 & 3.2 & 145 & 137 & 138 \\
\hline $\begin{array}{l}\mathrm{Na}^{+} \\
(136-146 \mathrm{mmol} / \mathrm{L})\end{array}$ & 155 & 151 & 150 & 143 & 5.7 & 3.8 & 3.2 \\
\hline $\begin{array}{l}\text { Calcium } \\
(2.2-2.6 \mathrm{mmol} / \mathrm{L})\end{array}$ & 2.2 & & & & & & \\
\hline $\begin{array}{l}\mathrm{Mg} \\
(0.62-0.95 \mathrm{mmol} / \mathrm{L})\end{array}$ & 0.78 & & & & & & \\
\hline $\mathrm{Pi}(0.81-1.4 \mathrm{mmol} / \mathrm{L})$ & 1.45 & & & & & & \\
\hline LDH (114-240 IU/L) & 506 & & & & 269 & & \\
\hline CK (25-200 U/L) & 363 & & & & 103 & & \\
\hline \multicolumn{8}{|l|}{ Urine } \\
\hline $\begin{array}{l}\text { Spot } \mathrm{K}^{+} \\
(25-120 \mathrm{mEq} / \mathrm{L})\end{array}$ & \multicolumn{7}{|c|}{30.5} \\
\hline $\begin{array}{l}\text { Spot } \mathrm{Na}^{+} \\
(40-220 \mathrm{mEq} / \mathrm{L})\end{array}$ & \multicolumn{7}{|c|}{116} \\
\hline Bence-Jones & \multicolumn{7}{|c|}{ Negative } \\
\hline Myoglobin & \multicolumn{7}{|c|}{ Negative } \\
\hline Heme & \multicolumn{7}{|c|}{ Negative } \\
\hline Eosinophils & \multicolumn{7}{|c|}{ Negative } \\
\hline Culture & \multicolumn{7}{|c|}{3 organisms } \\
\hline Stool occult blood & \multicolumn{7}{|c|}{ Negative } \\
\hline Endotracheal asp AFB & \multicolumn{7}{|c|}{ Negative } \\
\hline $\begin{array}{l}\text { Endotracheal asp } \\
\text { culture }\end{array}$ & \multicolumn{7}{|c|}{ Pseudomonas } \\
\hline $\mathrm{Hb}(130-160 \mathrm{~g} / \mathrm{L})$ & \multicolumn{7}{|c|}{81} \\
\hline TC $\left(3.50-9 \times 10^{9} / \mathrm{L}\right)$ & \multicolumn{7}{|c|}{10.2} \\
\hline Neutrophilia (\%) & \multicolumn{7}{|c|}{81} \\
\hline Plat $\left(165-415 \times 10^{9} / \mathrm{L}\right)$ & \multicolumn{7}{|c|}{100} \\
\hline MCV (79-93.3 fL) & \multicolumn{7}{|c|}{77} \\
\hline MCH (26.7-31.9 pg) & \multicolumn{7}{|c|}{27.8} \\
\hline MCHC (323-359 g/L) & \multicolumn{7}{|c|}{358} \\
\hline Reticulocyte (\%) & \multicolumn{7}{|c|}{0.5} \\
\hline INR & \multicolumn{7}{|c|}{1.3} \\
\hline aPTT (control 25.1 s) & \multicolumn{7}{|c|}{40} \\
\hline D dimer $(200 \mathrm{ng} / \mathrm{mL})$ & \multicolumn{7}{|c|}{3200} \\
\hline FDP & \multicolumn{7}{|c|}{ Positive } \\
\hline
\end{tabular}

TABLE 1: Continued.

\begin{tabular}{|c|c|c|c|c|c|c|}
\hline Day of admission & 1 & 4 & 5 & 10 & 16 & 18 \\
\hline Blood cultures & \multicolumn{6}{|c|}{ Sterile } \\
\hline dsDNA $(<20)$ & \multicolumn{6}{|c|}{28} \\
\hline ANA $(<1.0)$ & \multicolumn{6}{|c|}{1.8} \\
\hline cANCA & \multicolumn{6}{|c|}{ Negative } \\
\hline C3 (0.83-1.77 g/L) & \multicolumn{6}{|c|}{0.78} \\
\hline $\mathrm{C} 4(0.16-0.47 \mathrm{~g} / \mathrm{L})$ & \multicolumn{6}{|c|}{0.20} \\
\hline Cortisol $(5-25 \mu \mathrm{g} / \mathrm{dL})$ & \multicolumn{6}{|c|}{26.1} \\
\hline Ferritin $(28-397$ ng/L) & \multicolumn{6}{|c|}{1328} \\
\hline Direct Coombs & \multicolumn{6}{|c|}{ Negative } \\
\hline \multicolumn{7}{|l|}{ Cerebrospinal fluid } \\
\hline Cells & \multicolumn{6}{|c|}{103} \\
\hline Sugar (mg) & \multicolumn{6}{|c|}{115} \\
\hline Protein $(<60 \mathrm{mg})$ & \multicolumn{6}{|c|}{39} \\
\hline Lymphocytes $(<5)$ & \multicolumn{6}{|c|}{$100 \%$} \\
\hline $\mathrm{ADA}$ & \multicolumn{6}{|c|}{1.0} \\
\hline $\mathrm{AFB}$ & \multicolumn{6}{|c|}{ Negative } \\
\hline Gram & \multicolumn{6}{|c|}{ Negative } \\
\hline India ink & \multicolumn{6}{|c|}{ Negative } \\
\hline
\end{tabular}

HbAlc: glycated haemoglobin; bil: bilirubin; dir: direct; SGOT: serum glutamic oxaloacetic transaminase; SGPT: serum glutamic pyruvate transaminase; ALP: alkaline phosphatase; GGT: gamma-glutamyl transferase; $\mathrm{K}^{+}$: potassium; $\mathrm{Na}^{+}$: sodium; $\mathrm{Mg}$ : magnesium; Pi-inorganic phosphate; LDH: lactate dehydrogenase; $\mathrm{CK}$ : creatine kinase; $\mathrm{Hb}$ : haemoglobin; TC: total cells; plat: platelets; $\mathrm{MCV}$ : mean corpuscular volume; $\mathrm{MCH}$ : mean corpuscular haemoglobin; MCHC: mean corpuscular haemoglobin concentration; INR: international normalized ratio; aPTT: activated partial thromboplastin time; FDP: fibrinogen degradation products; dsDNA: double-stranded DNA; ANA: antinuclear antibody; c-ANCA: antineutrophil cytoplasmic autoantibody; C3: complement C3; C4: complement C4; $\mathrm{ADA}$ : adenosine deaminase; AFB: acid-fast bacilli; asp: aspirate.

and echocardiography were normal. Pending cultures, he was initiated on piperacillin-tazobactam and levofloxacin, along with subcutaneous heparin, warfarin, and pentoxifylline. CT chest (day2) showed bilateral pleural thickening, bilateral ground glassing (right $\gg$ left), airway dilatation, and reticulonodular infiltrates (right predominant) with minimal pleural effusion (Figure 1). In view of seizures, psychosis, thrombocytopenia, renal failure, pneumonitis, ANA, and dsDNA positivity, a diagnosis of systemic lupus was made and pulse methyl prednisolone ( $\mathrm{g} \times 3$ days) was initiated on day 3 , followed by oral steroids $(60 \mathrm{mg})$. Tracheal aspirate grew Pseudomonas aeruginosa and imipenem was administered on day 5 for probable ventilator-associated pneumonia. Weaning was done on 8th day of admission. Fluconazole $300 \mathrm{mg} /$ day was administered for persisting candiduria. Hypernatremia was managed with dextrose saline, while sugars were controlled with infusion of regular insulin. By day 12, his power had improved to 3/5 in all limbs; he occasionally spoke a few words to his relatives but continued to be extremely afraid of hospital personnel. MRI and nerve conduction studies could not be performed due to poor cooperation. He developed an infected gluteal bedsore (E. coli) that necessitated amikacin. We acceded to his son's request to be discharged to home with modified doses of intramuscular amikacin therapy, twicedaily premixed insulin, warfarin, phenytoin, risperidone, 
clonezepam, and oral prednisolone $40 \mathrm{mg} / \mathrm{day}$. Seventeen days later he succumbed to another respiratory infection.

\section{Discussion}

The 9:1 female predominance in SLE decreases prior to puberty and late in life [4]. Female: male ratio in late-onset SLE is about 5:1 [5], while another study showed a ratio of $1: 1.1$ when the age of onset was $>65$ years [6]. Four to $18 \%$ of cases from reported series are male [7]. In a Hong Kong study, the mean age of late-onset SLE was 62 years and onset was generally insidious [1]. Insidious onset of disease and lower index of suspicion lead to delayed diagnosis in the elderly. A study of 39 Indian male SLE subjects showed only one patient with late-onset SLE [8].

It is generally agreed that SLE in the elderly is a mild disease [9]. Prevalence of organ involvement in males depends upon the ethnic population being studied, study setting (tertiary versus primary), selection criteria of female controls, and sample size of male subjects [10]. Fever, fatigue, and weight loss are common symptoms in elderly SLE patients [5]. Serositis, muscle pains, and arthritis are more common in this age group as are secondary Sjögren's syndrome but with a lower incidence of cutaneous manifestations and Raynaud's phenomenon [9]. Males in a Thai study tended to have a shorter duration of symptoms prior to presentation, with alopecia, arthralgia and Raynaud's phenomenon being less common [10]. Psychosis, hypocomplementemia, and diffuse proliferative glomerulonephritis (DPGN) were less common in Indians [8], while renal disease and vascular thrombosis were common among Latin American males [11]. Rheumatoid arthritis, polymyalgia rheumatic, and sicca syndromes are close differentials of SLE in the elderly [5]. Late-onset lupus may have fewer major organ involvement and fewer major relapses [12].

Among patients with SLE, $60 \%$ of adults develop kidney disease [2]. SLE prevalence in India was low at 3.2/100000 population [13]; contrastingly, renal involvement among Indian SLE patients was the highest in the world [13]. Neuropsychiatric manifestations are similar in the young and the elderly [9]. Neuropsychiatric SLE (NSLE) at presentation in the elderly population has been described only as case reports. Similar to our case, seizures, coma, and pneumonia have been reported in a 72-year-old lady who had pneumonitis, hypocomplementemia, elevated fibrinogen, and FDP but with normal renal function and negative dsDNA [14]. Presence of NSLE is generally associated with a poor prognosis [9]. NSLE can be either focal (stroke, neuropathy, and transient ischemic attack) or diffuse (confusion, dementia, and psychosis) or can present with seizures (partial or generalized) [9]. Seizures are reported in 15 to $30 \%$ of patients with SLE [9]. Cognitive impairment may be the initial manifestation of SLE in the elderly [5]. The neurological manifestations seen in Indian studies were cerebrovascular accidents, myeloradiculopathies, movement disorders, seizures, coma, and psychosis [13]. Lower numbers of Raynaud and NSLE were seen in the South Indian population [13]. Our patient's cognition did not improve completely at time of discharge.
His respiratory symptoms could have also been contributed by diabetes-related pneumonia or seizure-related aspiration pneumonia but his chest radiograph (Figure 1) cleared on the 4th day of admission (after two methyl prednisolone pulses). The cause of foot gangrene could not be pinpointed. Antiphospholipid antibody testing was unavailable in our hospital. Since warfarin had been initiated prior to admission, protein $\mathrm{C}$ and protein $\mathrm{S}$ were not done. High levels of Ddimer and FDP like in our patient may indicate vascular involvement due to emboli and/or inflammation [14]. It is possible that diabetes, old age, smoking, sepsis, and SLE predisposed him towards thrombosis.

Age did not affect serological findings in a study [5]. False positive ANA can be seen in the elderly [5]. Prevalence of dsDNA positivity and hypocomplementemia may be lower $[5,9]$ and complement levels are inversely proportional to the age [9]. Our patient's C3 levels were borderline low, while ANA and dsDNA were positive. Anti-Ro and antiLa antibodies can be useful adjuncts in the elderly when dsDNA levels are less frequently positive [9]. The American Rheumatological Association (ARA) criteria may be too strict in the elderly population with NSLE and hence more attention is given to serology in the elderly [15]. Also, patients may not satisfy the current ARA classification criteria at presentation and hence diagnosis may be uncertain; they would need a longer duration of followup for the diagnosis to be made [12].

CNS disease and renal involvement contributed towards mortality [3]. Nonrenal factors like younger age, male sex, and hematological complications like thrombocytopenia were prognostic factors in lupus nephritis [2]. Cardiovascular disease and infections are common causes of mortality in the elderly [5]. In a retrospective Indian study, mortality in SLE patients was due to disease activity, infection, or both [3]. Hospital-acquired Gram-negative septicaemia contributed most in this study. Our patient had disease activity along with candiduria and Pseudomonas-related pneumonia which improved prior to discharge, but our patient finally succumbed to an infection. Septic shock due to high-dose immunosuppressants was the major cause of morality in older-onset SLE.

In conclusion, we report an elderly male diabetic with late-onset NSLE, gangrene, and sepsis (respiratory and urinary) that improved with immunosuppressant therapy. Systemic lupus erythematosus is an autoimmune disease involving women of childbearing age with highly variable clinical presentations and with $10 \%$ of cases occurring in older patients. Arthritis, fever, serositis, Raynaud's syndrome, lung disease, neuropsychiatric symptoms, positive antinuclear antibody tests, positive rheumatoid factor, positive antiRo/Sjögren's syndrome (SS) A, and positive anti-La/SSB are more common in patients with elderly-onset lupus. Autoimmune diseases are very rare in elderly males and need to be considered in the differential diagnoses when confronted with multisystem disease even in the presence of diabetes and systemic sepsis. The diagnosis of elderly-onset lupus is often delayed for several months because of insidious onset and similarity to other more common disorders. 


\section{Conflict of interests}

The authors declare that they have no conflict of interests.

\section{References}

[1] S. K. Mak, E. K. M. Lam, and A. K. M. Wong, "Clinical profile of patients with late-onset SLE: not a benign subgroup," Lupus, vol. 7, no. 1, pp. 23-28, 1998.

[2] C. Molino, F. Fabbian, and C. Longhini, "Clinical approach to lupus nephritis: recent advances," European Journal of Internal Medicine, vol. 20, no. 5, pp. 447-453, 2009.

[3] A. Sharma, S. B. Shamanna, S. Kumar et al., "Causes of mortality among inpatients with systemic lupus erythematosus in a tertiary care hospital in North India over a 10 -year period," Lupus, vol. 22, no. 2, pp. 216-222, 2013.

[4] C. C. Mok, C. S. Lau, T. M. Chan, and R. W. S. Wong, "Clinical characteristics and outcome of southern Chinese males with systemic lupus erythematosus," Lupus, vol. 8, no. 3, pp. 188-196, 1999.

[5] D. Lazaro, "Elderly-onset systemic lupus erythematosus: prevalence, clinical course and treatment," Drugs and Aging, vol. 24, no. 9, pp. 701-715, 2007.

[6] S. J. Pu, S.-F. Luo, Y. J. J. Wu, H. S. Cheng, and H. H. Ho, “The clinical features and prognosis of lupus with disease onset at age 65 and older," Lupus, vol. 9, no. 2, pp. 96-100, 2000.

[7] G. Medina, O. Vera-Lastra, L. Barile, M. Salas, and L. J. Jara, "Clinical spectrum of males with primary antiphospholipid syndrome and systemic lupus erythematosus: a comparative study of 73 patients," Lupus, vol. 13, no. 1, pp. 11-16, 2004.

[8] I. Pande, A. N. Malaviya, N. G. Sekharan, S. Kailash, S. S. Uppal, and A. Kumar, "SLE in indian men: analysis of the clinical and laboratory features with a review of the literature," Lupus, vol. 3, no. 3, pp. 181-186, 1994.

[9] M. Dennis, "Neuropsychiatric lupus erythematosus and the elderly," International Journal of Geriatric Psychiatry, vol. 9, no. 2, pp. 97-106, 1994.

[10] J. Mongkoltanatus, S. Wangkaew, N. Kasitanon, and W. Louthrenoo, "Clinical features of Thai male lupus: an age-matched controlled study," Rheumatology International, vol. 28, no. 4, pp. 339-344, 2008.

[11] M. A. Garcia, J. C. Marcos, A. I. Marcos et al., "Male systemic lupus erythematosus in a Latin-American inception cohort of 1214 patients," Lupus, vol. 14, no. 12, pp. 938-946, 2005.

[12] C. T. K. Ho, C. C. Mok, C. S. Lau, and R. W. S. Wong, "Late onset systemic lupus erythematosus in southern Chinese," Annals of the Rheumatic Diseases, vol. 57, no. 7, pp. 437-440, 1998.

[13] A. N. Malaviya, A. N. Chandrasekaran, A. Kumar, and P. N. Shamar, "Occasional series-lupus around the world systemic lupus erythematosus in India," Lupus, vol. 6, no. 9, pp. 690-700, 1997.

[14] M. Yamaya, M. Yoshida, M. Yamasaki, H. Kubo, K. Furukawa, and H. Arai, "Seizure and pneumonia in an elderly patient with systemic lupus erythematosus," Journal of the American Geriatrics Society, vol. 57, no. 9, pp. 1709-1711, 2009.

[15] M. S. Dennis, E. J. Byrne, N. Hopkinson, and P. Bendall, "Neuropsychiatric systemic lupus erythematosus in elderly people: a case series," Journal of Neurology Neurosurgery and Psychiatry, vol. 55, no. 12, pp. 1157-1161, 1992. 


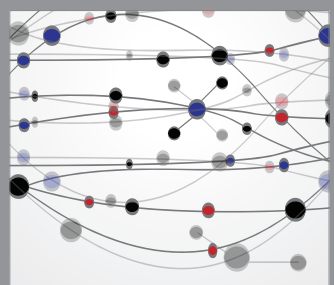

The Scientific World Journal
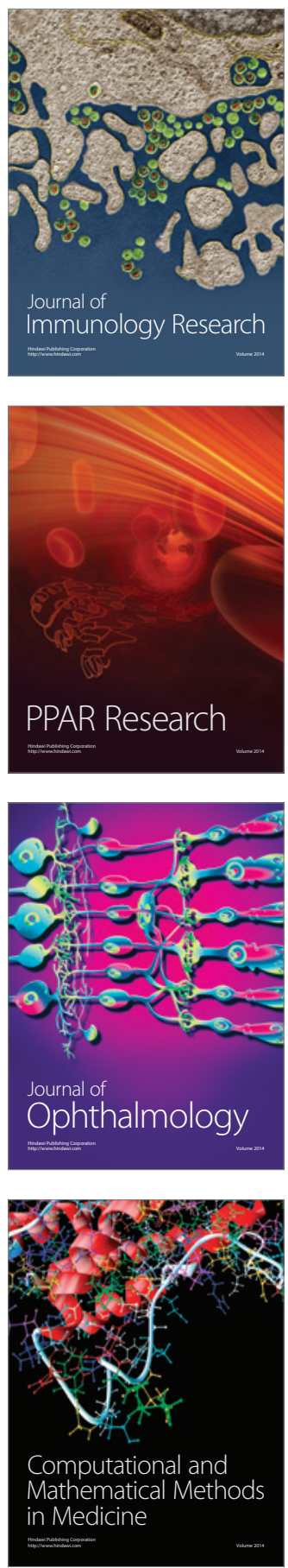

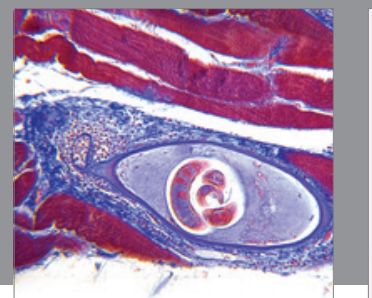

Gastroenterology

Research and Practice
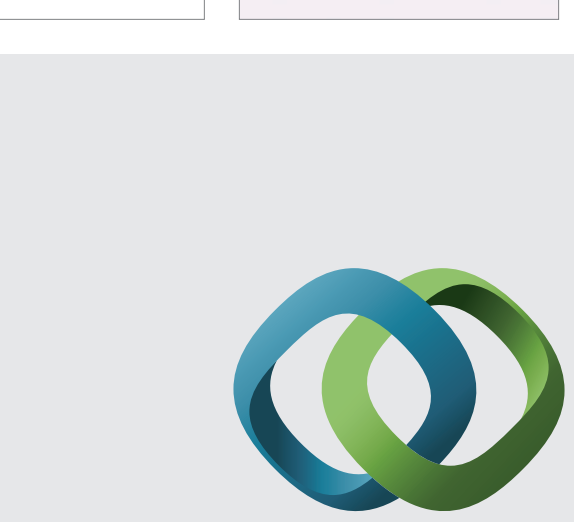

\section{Hindawi}

Submit your manuscripts at

http://www.hindawi.com
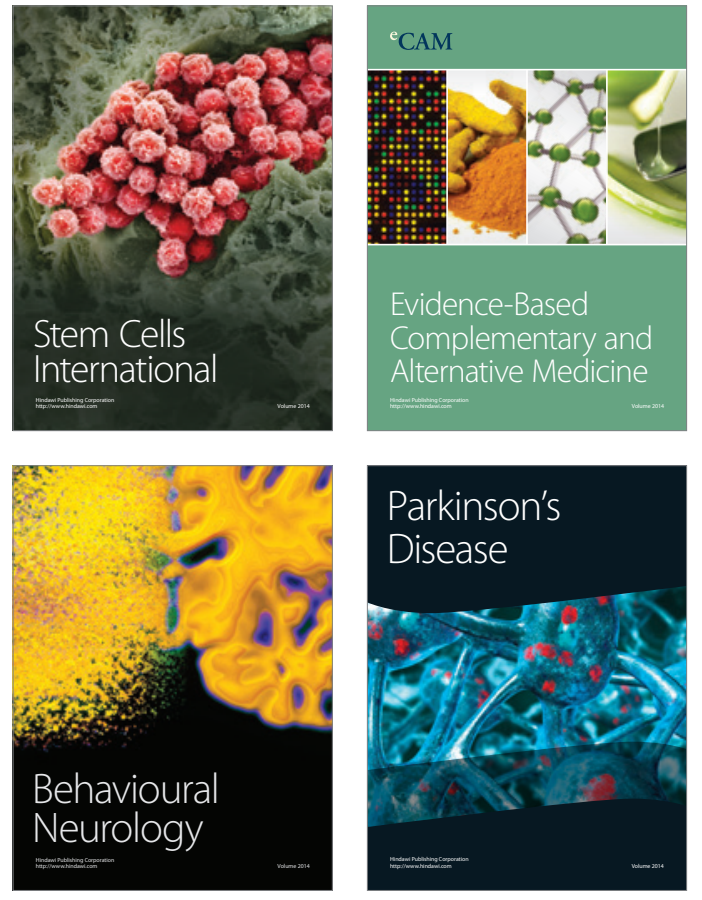
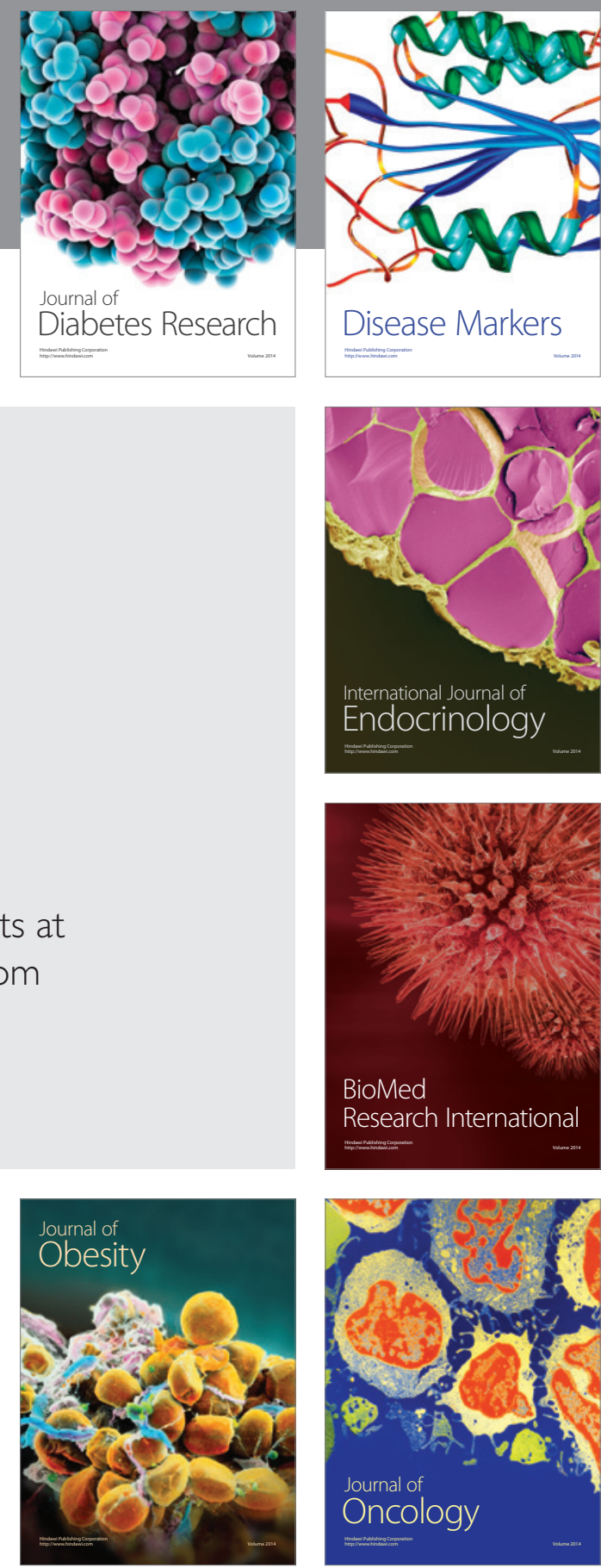

Disease Markers
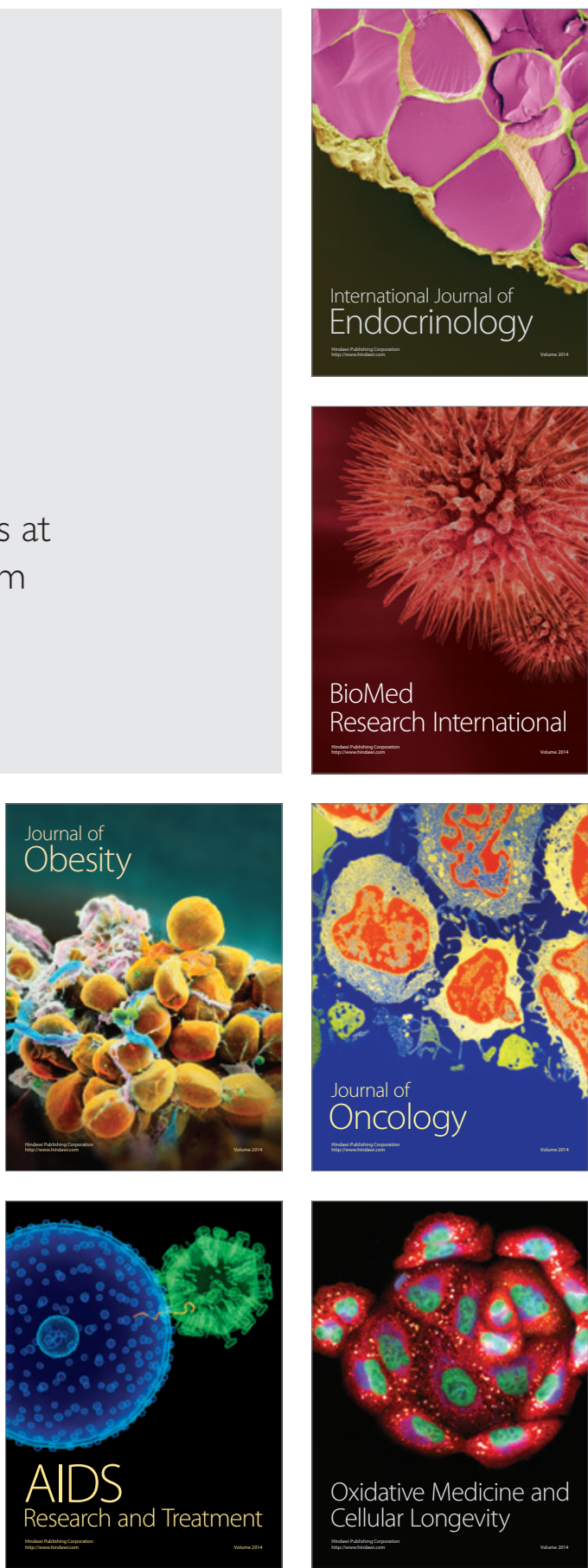